\title{
ANALISIS DAYA DAN EFISIENSI TURBIN AIR KINETIS AKIBAT PERUBAHAN PUTARAN RUNNER
}

\author{
Arief Muliawan', Ahmad Yani' \\ ${ }^{1)}$ Teknik Elektro, Sekolah Tinggi Teknologi Bontang \\ Jalan Ir. H. Juanda No. 73 RT.36 Bontang \\ ${ }^{2)}$ Teknik Mesin, Universitas Trunajaya Bontang \\ Jalan Taekwondo No. 55 RT.9 Bontang \\ Email: ariefstitek@gmail.com
}

\begin{abstract}
Research has been conducted about change power and efficiency on turbine. Manufacture of turbine singer aims to determine the magnitude of the reviews on power output and efficiency due to the rotation of the turbine runner. Turbine runner done with variation $90 \mathrm{rpm}, 70 \mathrm{rpm}, 50 \mathrm{rpm}$, $30 \mathrm{rpm}$ and $10 \mathrm{rpm}$. Of the various rounds of runner that shows the maximum power change occurred on lap $50 \mathrm{rpm}, 70 \mathrm{rpm}$ and $90 \mathrm{rpm}$. Maximum power lead to speed with discharge runners $70 \mathrm{rpm}$ flow $0.0078 \mathrm{~m} 3 / \mathrm{s}$ at 4,572 watts. Power generated minumum on debit $0.0078 \mathrm{~m} 3 / \mathrm{s}$ occurred on speed runner $90 \mathrm{rpm}$ of 3,674 watts. Maximum turbine efficiency occurs debit on flow $0.0078 \mathrm{~m} 3 / \mathrm{s}$ and $70 \mathrm{rpm}$ with a value of $28.342 \%$, and then declined in round $50 \mathrm{rpm}$ amounted to $24.477 \%$ and the lowest in round $90 \mathrm{rpm}$ amounted to $23.189 \%$. From the calculation of the efficiency obtained maximum value is obtained at a speed of $70 \mathrm{rpm}$ with a flow runner debit $0.0078 \mathrm{~m} 3 / \mathrm{s}$.
\end{abstract}

Key words: power, efficiency, kinetic turbines

\section{PENDAHULUAN}

Pengembangan potensi sumber-sumber energi seperti energi angin, energi air, energi matahari, biogas, dan sebagainya untuk kebutuhan energi listrik di daerah-daerah terpencil yang potensinya cukup besar sementara pemanfaatannya belum maksimal untuk kesejahteraan masyarakat. Pengembangan turbin air misalnya yang memiliki potensi yang cukup besar untuk pembangkitan energi listrik.

Pembangkit listrik tenaga air telah banyak dilakukan pengembangan di berbagai daerah di Indonesia, terutama turbin air tipe aliran silang (crossflow) yang aplikasinya mencakup semua lokasi dengan debit aliran air dan head atau tinggi jatuh air yang rendah dan menengah (Haimerl, L.A. 1960: 3). Di dalam turbin energi kinetik air dirubah menjadi energi mekanik, dimana air memutar roda turbin (Arismunandar, 1982). Energi puntir yang dihasilkan selanjutnya diubah menjadi energi listrik melalui generator (Luknanto, 2008). Namun demikian selama ini energi air yang digunakan adalah air dengan tinggi jatuh dan debit besar. Sementara itu energi air dengan tinggi jatuh dan debit kecil belum banyak dimanfaatkan, padahal di beberapa wilayah Indonesia punya potensi yang cukup besar untuk dikembangkan pembangkit listrik tenaga air dengan tinggi jatuh dan debit kecil (microhydro) (Triono, 2012:112)

Turbin ini sangat tepat untuk dipakai pada daerah yang datar yang memiliki aliran sungai, terutama daerah pedesaan. Sampai saat ini dikenal dua jenis turbin kinetik, yaitu turbin kinetik dengan poros horizontal dan turbin kinetik berporos vertikal. Menurut Soenoko 
(2012), banyak keuntungan yang diperoleh apabila turbin kinetik ini dipakai sebagai pembangkit listrik. Keuntungan pemanfaatan turbin kinetik adalah (1) Pemilihan lokasi tidak terlalu banyak syarat; (2) Tanpa bendungan; (3) Instalasi yang murah; (3) Waktu pemasangan yang cepat; (4) Keluaran energi yang mudah di skala (easily scalable energi output); (5) Kapasitas yang steady, produksi energi yang steady; (6) Bentuknya sederhana dan mudah dibuat; (7) Potensi air yang dibutuhkan tidak membutuhkan tinggi jatuh, yang dibutuhkan hanya adanya aliran air (energi kinetik); (8) Tegangan listrik yang dibangkitkan adalah DC; (9) Pemeliharaan mudah dan (10) Untuk setiap aliran sungai dapat dipasang beberapa instalasi turbin kinetik. Sehingga listrik yang dibangkitkan akan berlipat sesuai dengan banyaknya turbin yang dipasang pada aliran sungai tersebut.

Berdasarkan penelitian yang dilakukan oleh Bono dan Indarto (2008), menyimpulkan bahwa karakteristik daya dan efesiensi antara sudu mangkuk dan setengah silinder hampir sama, namun daya dan efesiensi sudu mangkuk lebih baik dari sudu setengah silinder dan Hasil penelitian Raharjo (2008), menunjukkan ada perbedaan yang signifikan antara efisiensi turbin air menggunakan profil sudu bilah sejajar, profil sudu bilah tegak lurus, dan profil sudu mangkuk ternyata profil sudu mangkuk lebih baik dari yang lainya. Sudu berbentuk mangkuk diharapkan agar aliran fluida yang menumbuk sudu tersebut akan memperbesar gaya tangensial akibat dari adanya kelengkungan sudu yang memperlambat posisi aliran air keluar sehingga menpunyai energi yang cukup berarti yang dapat meningkatkan kinerja turbin.

Turbin yang memiliki fungsi sebagai pembangkit listrik, dimana turbin kinetik ini memanfaatkan kecepatan aliran air dari sungai, air yang mengalir melewati sudu-sudu mengalami perubahan momentum yang dapat memberikan gaya dorong pada sudu sehingga runner berputar. Di sini terjadi perubahan energi kinetik air menjadi energi mekanis pada turbin yang digunakan untuk menggerakkan generator sehingga menjadi energi listrik. Dimana perubahan energi tersebut terjadi pada sudu-sudu turbin. Pada turbin kinetik poros vertikal air langsung menumbuk sudu pada setengah bagian roda turbin sedangkan setengah bagian yang lain juga mendapat tumbukan tetapi tidak sebesar setengah bagian yang pertama sehingga turbin masih bisa berputar. Turbin yang di pergunakan dalam penelitian ini adalah turbin kinetik yang porosnya diletakan secara vertikal.

\section{METODE PENELITIAN}

\section{Alat Penelitian}

Bagian terpenting dari peralatan ini yakni Runner meliputi 3 bagian utama, yaitu poros berdiameter $30 \mathrm{~mm}$, cakram berdiameter 110 $\mathrm{mm}$ dan tinggi cakram $130 \mathrm{~mm}$ dengan bahan pipa besi setebal $4 \mathrm{~mm}$, dan sudu panjangnya $110 \mathrm{~mm}$, lebar $130 \mathrm{~mm}$ dan kedalaman sudu mangkuk $23 \mathrm{~mm}$. sudu yang berjumlah sembilan buah setebal $3 \mathrm{~mm}$ dengan bahan mika transparan yang dipasang keliling cakram. Gambar cakram, poros, bentuk sudu dan variasi sudu turbin kinetik sebagaimana ditunjukkan pada Gambar 1.

Selanjutnya saluran aliran air mempunyai ukuran panjang $2500 \mathrm{~mm}$, lebar $550 \mathrm{~mm}$, dan tinggi $250 \mathrm{~mm}$ yang terbuat dari kayu setebal $25 \mathrm{~mm}$. namun saluran aliran air yang dipakai untuk penelitian hanya panjang $1600 \mathrm{~mm}$ dan lebar saluran air masuk sebesar $200 \mathrm{~mm}$ sedangkan lebar saluran masuk yang menumbuk sudu turbin sebesar $100 \mathrm{~mm}$ dengan kemiringan $4,2^{\circ}$. Saluran aliran air sebagaimana ditunjukkan pada Gambar 2 dan 3. 


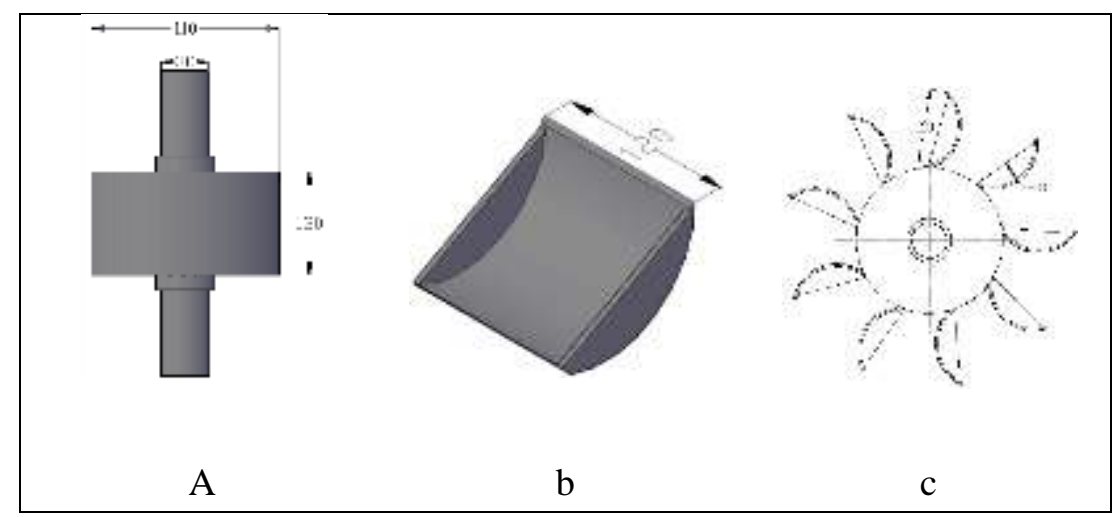

Gambar 1 a. Cakram dan poros, b. Sudu Turbin, c. Runner turbin

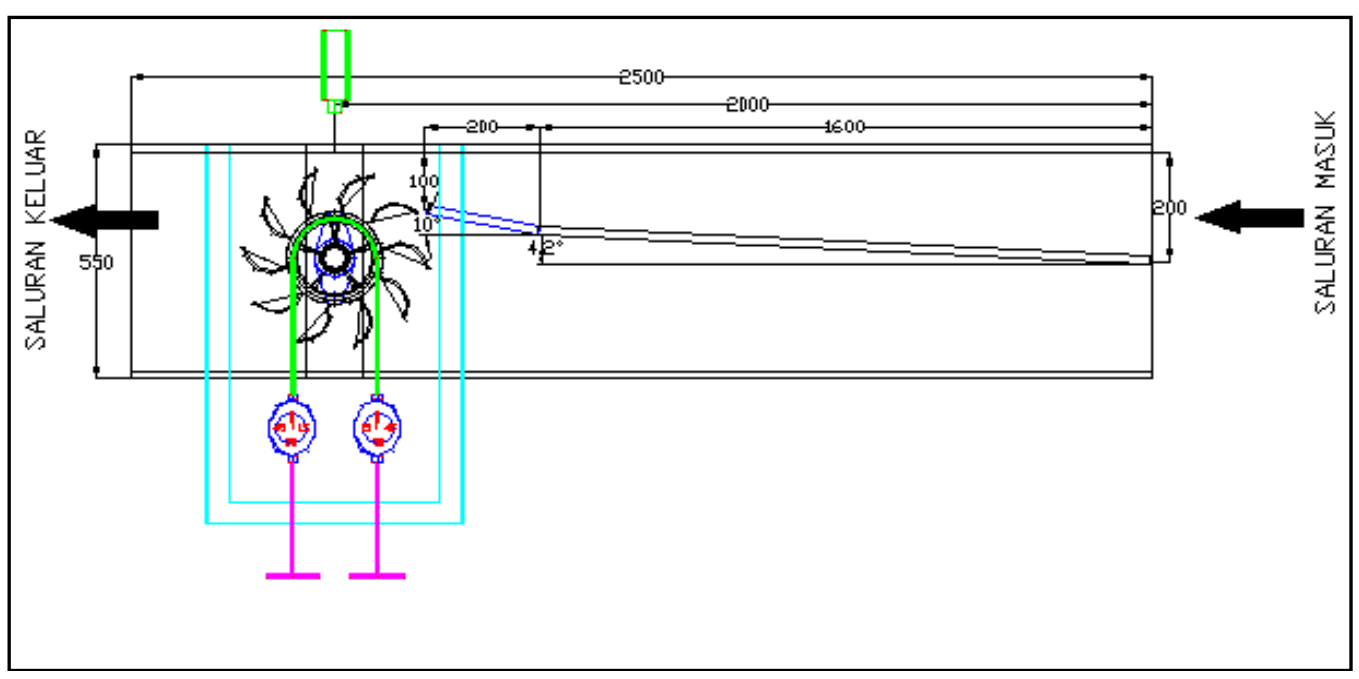

Gambar 2. Instalasi penelitian tampak atas.

\section{Variabel Masukan}

Penelitian ini diawali dengan mengetahui luas penampang dan kecepatan aliran. Persamaan untuk menghitung luas saluran masuk pada sudut pengarah aliran adalah:

$A=p . l$

Untuk menghitung kecepatan aliran pada posisi sudut pengarah aliran digunakan persamaan:

$$
v_{1}=\frac{\mathrm{Q}}{\mathrm{A}}
$$

Dengan Q adalah debit aliran yang digunakan dalam penelitian ini. Selanjutnya dapat dihitung laju massa air yang mengalir persatuan waktu adalah

$$
\dot{m}=\rho \cdot Q \cdot v
$$

Dengan $\rho$ massa jenis air. Pada penelitian ini digunakan untuk turbin ini yakni saluran terbuka sehingga tidak ada beda tekanan. Persamaan energi yang digunakan dalam turbin kinetik adalah energi kinetik. Dalam hal ini energi yang tersedia merupakan energi kinetik. Besarnya energi yang dihasilkan oleh suatu aliran ditentukan dengan (Zahir dan Bambang, 2010)

$\mathrm{E}_{\mathrm{k}}=\frac{1}{2} \cdot m \cdot v^{2}$ 


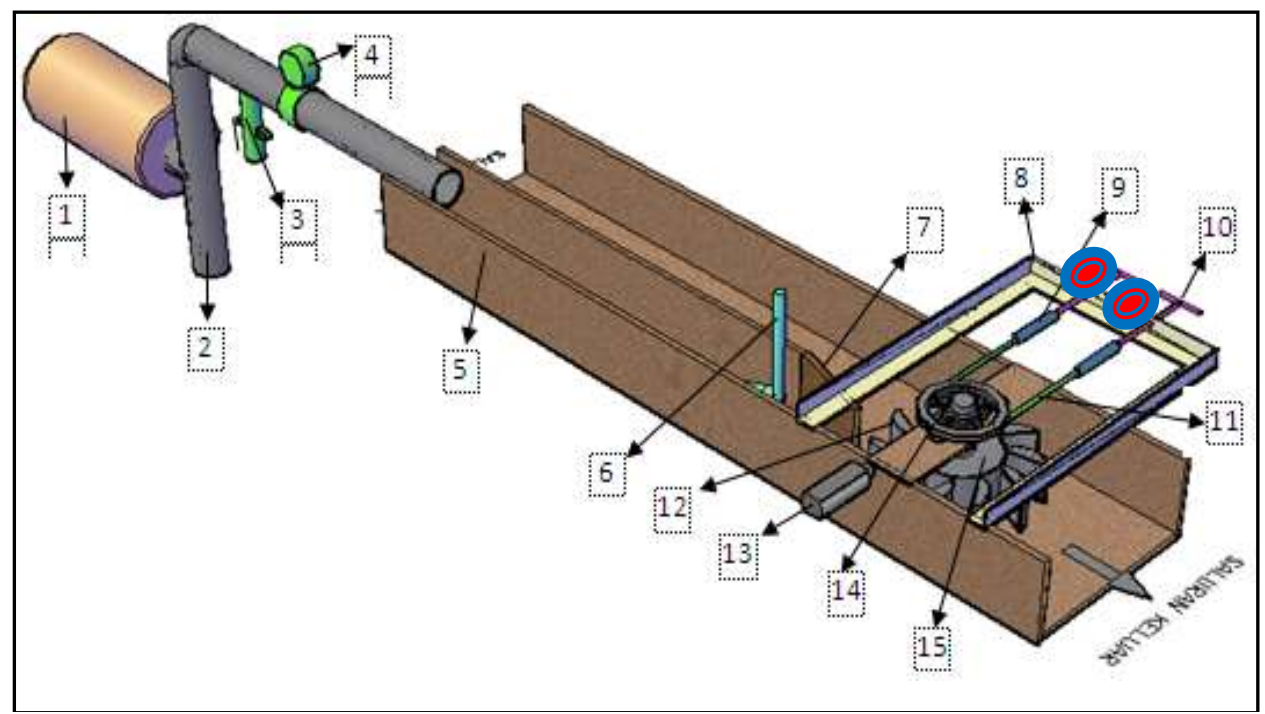

Gambar 3. Instalasi penelitian tampak tiga dimensi.

Keterangan : (1) Pompa air; (2) Pipa hisap; (3) Katup buangan (Penyetel debit); (4) Flowmeter; (5) Saluran turbin; (6) Flowatch; (7) Pengarah aliran; (8) Dudukan tuas penyetel beban gaya; (9) Neraca pegas; (10) Tuas penyetel beban gaya; (11) Tali; (12) Sudu turbin; (13) Tachometer; (14) Pully dan (15) Runner / roda Turbin

Untuk turbin kinetik yang hanya memanfaatkan aliran air atau kecepatan arus sungai, energi air yang tersedia merupakan energi kinetik. Sebagaimana ditunjukkan pada $\frac{\mathrm{E}_{\mathrm{k}}}{\mathrm{t}}=\frac{1}{2} \cdot \dot{m} \cdot v^{2}$

Untuk daya air yang mengalir pada suatu penampang saluran tertentu maka dalam perhitunganya dipergunakan (Kadir dan Bambang, 2010)

$\mathrm{P}_{\mathrm{a}}=\frac{1}{2} \cdot \rho \cdot Q \cdot v^{2}$

atau dengan menggunakan persamaan kontinuitas $\mathrm{Q}=A \cdot v$ maka:

$\mathrm{P}_{\mathrm{a}}=\frac{1}{2} \cdot \rho \cdot A \cdot v^{3}$

Untuk menghitung besar daya turbin yang dihasilkan akibat adanya energi kinetik dipergunakan perumusan (Arismunandar,2004) $\mathrm{P}_{\mathrm{t}}=T . \omega$

Maka untuk mendapatkan torsi yang merupakan gaya dikali dengan lengan radius pully yang besar lengan $(0,13 \mathrm{~m})$, besarnya torsi dapat dihitung dengan persamaan
$T=F_{t} \cdot R$

Kecepatan keliling turbin atau dikenal dengan kecepatan sudut dapat diperoleh dengan menghitung

$$
\omega=\frac{2 . \pi \cdot n}{60}
$$

Daya yang dihasilkan oleh turbin sebesar

$P_{t}=T . \omega$

Efesiensi turbin dapat dihitung dengan persamaan:

$\eta_{t}=\frac{P_{t}}{P_{a}} \times 100 \%$

\section{Prosedur Penelitian}

Langkah penelitian adalah (1) Membuat Tabel untuk mencatat hasil pengujian; (2) Menyiapkan dan memasang semua instalasi penelitian dengan variasi sudut pengarah aliran yang di tentukan; (3) Memasang alat ukur yang dibutuhkan; (4) Mengecek kondisi alat ukur dan alat pendukung lainnya yang digunakan dalam pengambila data; (5) Memasang sudu berjumlah Sembilan buah; (6) 
Menghidupkan pompa untuk menyalurkan air; (7) Mengatur debit aliran dengan cara memutar kran sesuai dengan debit yang di inginkan sebagaimana ditunjukkan pada komponen instalasi (instalasi penelitian tampak tiga dimensi); (8) Mengukur putaran poros turbin dengan alat ukur tacometer tanpa beban terlebih dahulu sebagaimana ditunjukkan pada komponen instalasi penelitian. Selanjutnya mengukur putaran poros turbin dengan beban yang diberikan secara pelan-pelan dengan cara memutar tuas penyetel beban gaya sampai memenuhi putaran yang divariasi dan selanjutnya memberikan beban sebagaimana ditunjukkan pada komponen instalasi penelitian - Sampai turbin tidak berputar. Kemudian mencatat setiap variasi pengukuran putaran turbin sampai turbin berhenti berputar; (9) Pengujian putaran runner atau poros turbin yang $90 \mathrm{rpm}$ dilakukan 3 kali pengulangan untuk mendapatkan data pengujian yang akurat; (10) Mengulang langkah nomor satu sampai dengan ketiga pada variasi putaran poros turbin untuk 90, 70, 50, 30 dan $10 \mathrm{rpm}$; (11) Mengolah data penelitian yang didapatkan dan (12) Menganalisa data penelitian yang didapatkan untuk mengetahui hubungan antara variabel yang telah ditentukan.

\section{HASIL DAN PEMBAHASAN}

Turbin air yang diteliti adalah jenis turbin kinetik yang berbentuk roda dengan sudut pada sekeliling tepi tepinya yang diletakkan pada poros vertikal dengan sambungan engsel. Salah satu bagian utama dari turbin kinetik ini adalah runner. Dimana runner memiliki tiga bagian utama yaitu:

Bagian yang pertama dari runner adalah poros, dimana poros berfungsi untuk menahan bagian-bagian dari runner yang ditempatkan pada bearing, sehingga air yang mengalir melewati sudu-sudu dapat memberikan gaya dorong pada sudu sehingga runner berputar.
Poros turbin terbuat dari baja dengan ukuran diameter $30 \mathrm{~mm}$ dan panjangnya $130 \mathrm{~mm}$ dan porosnya diletakan secara vertikal dengan harapan agar pemasangan generator lebih mudah, seluruh sudu mendapat dorongan dari aliran air, dan pemasangan seluruh instalasi turbin menjadi lebih mudah.

Bagian kedua dari runner adalah cakram. Dimana sudu-sudu akan dikeling sekeliling cakram dengan jarak yang sama antara sudu satu dengan lainnya. Cakram turbin berbentuk selindris yang terbuat dari pipa besi berdiameter $110 \mathrm{~mm}$, tebalnya $4 \mathrm{~mm}$ dan panjangnya 130 $\mathrm{mm}$.

Bagian yang ketiga dari runner adalah sudu, dimana sudu-sudu ini berfungsi untuk memindahkan energi kinetik aliran air kepada runner. Sudu-sudu ini berbentuk mangkuk yang dipasang dengan engsel pada cakram dan dipasang sejajar dengan sumbu poros turbin. Sudu berbentuk mangkuk diharapkan agar aliran fluida yang menumbuk sudu mempunyai energi mekanik yang cukup berarti yang dapat meningkatkan kinerja turbin. Sudu terbuat dari akrilik/mika yang transparan dengan ketebalan $3 \mathrm{~mm}$.

Penelitian dilakukan dengan mengalirkan fluida air pada saluran turbin yang telah disiapkan dengan mempergunakan pompa, fluida yang dialirkan dibuat turbulensi agar kondisinya dianggap sama dengan kondisi sungai yang mengalir. Debit air ditetapkan $0,0153 \mathrm{~m}^{3} / \mathrm{s}$. Sedangkan variasi pengereman putaran turbin terdiri dari $90,70,50,30$, dan $10 \mathrm{rpm}$.

Proses penelitian dengan melakukan pengujian terhadap turbin air kinetik. Pengujian ini dilakukan untuk mendapatkan data putaran (n), gaya (F) dan perhitungan terhadap kecepatan aliran pada saluran masuk di ujung pengarah aliran $(\mathrm{V})$, dengan posisi komponen tersebut sebagaimana ditunjukan pada Gambar 4. 


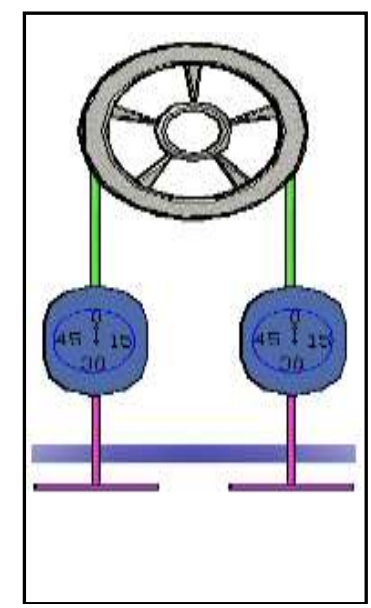

Gambar 4. Posisi dan Arah Gaya pada Penelitian

Tabel 1. Hasil data hasil pengujian debit $28 \mathrm{~m}^{3} / \mathrm{jam}$ atau $0.0078 \mathrm{~m}^{3} / \mathrm{s}$

\begin{tabular}{ccccccc}
\hline \multicolumn{2}{c}{ Debit Aliran } & Putaran & \multicolumn{3}{c}{ Gaya F $(\mathrm{N})$} \\
\cline { 1 - 1 } \cline { 5 - 6 } $\mathrm{Q}\left(\mathrm{m}^{3} / \mathrm{jam}\right)$ & $\mathrm{Q}\left(\mathrm{m}^{3} / \mathrm{s}\right)$ & & $\mathrm{F} 1$ & $\mathrm{~F} 2$ & $\Sigma \mathrm{F}$ \\
\hline 28.000 & 0.0078 & 90 & 0.9 & 2.1 & 3.0 \\
28.000 & 0.0078 & 90 & 0.9 & 2.2 & 3.1 \\
28.000 & 0.0078 & 90 & 0.8 & 2.2 & 3.0 \\
28.000 & 0.0078 & 70 & 1.5 & 3.2 & 4.7 \\
28.000 & 0.0078 & 70 & 1.4 & 3.3 & 4.7 \\
28.000 & 0.0078 & 70 & 1.4 & 3.4 & 4.8 \\
28.000 & 0.0078 & 50 & 2.2 & 4.4 & 6.6 \\
28.000 & 0.0078 & 50 & 2.2 & 3.5 & 5.7 \\
28.000 & 0.0078 & 50 & 2.2 & 3.4 & 5.6 \\
28.000 & 0.0078 & 30 & 3.0 & 5.0 & 8.0 \\
28.000 & 0.0078 & 30 & 3.0 & 5.1 & 8.1 \\
28.000 & 0.0078 & 30 & 2.9 & 5.1 & 8.0 \\
28.000 & 0.0078 & 10 & 4.0 & 5.7 & 9.7 \\
28.000 & 0.0078 & 10 & 4.1 & 5.7 & 9.8 \\
28.000 & 0.0078 & 10 & 3.9 & 5.8 & 9.7 \\
\hline
\end{tabular}

Dari penelitian yang dilakukan yakni melakukan pengujian terhadap instalasi turbin dengan memvariasikan debit air dimana $\sum \mathrm{F}=$ $\mathrm{F}_{1}+\mathrm{F}_{2}$ maka diperoleh contoh data di Tabel 1 .

Dari data diatas kemudian dilakukan pengukuran gaya gaya untuk debit $0,0067 \mathrm{~m}^{3} / \mathrm{s}$ dan $0,0056 \mathrm{~m}^{3} / \mathrm{s}$ dengan perlakuan yang sama.
Setelah diperoleh data pengukuran gaya kemudian menghitung besarnya daya dan efisiensi dari runner turbin. Besarnya daya yang dihasilkan oleh runner turbin ditunjukan pada tabel 2. 
Muliawan, A., \& Yani, A., 2016. Analisis Daya dan Efisiensi Turbin Air Kinetis Akibat Perubahan Putaran Runner. Journal of Sainstek, 8(1): 1-9.

Tabel 2. Data daya tiap putaran runner turbin terhadap debit air.

\begin{tabular}{cccccc}
\hline Debit, & \multicolumn{5}{c}{ Daya P (watt) } \\
\cline { 2 - 6 } $\mathrm{Q} \mathrm{m}^{3} / \mathrm{s}$ & $90 \mathrm{rpm}$ & $70 \mathrm{rpm}$ & $50 \mathrm{rpm}$ & $30 \mathrm{rpm}$ & $10 \mathrm{rpm}$ \\
\hline & 1.592 & 2.095 & 2.245 & 1.510 & 0.667 \\
$0,0056 \mathrm{~m}^{3} / \mathrm{s}$ & 1.470 & 2.095 & 2.177 & 1.510 & 0.667 \\
& 1.470 & 2.095 & 2.177 & 1.470 & 0.667 \\
\hline & 3.306 & 3.429 & 3.198 & 2.408 & 0.871 \\
$0,0067 \mathrm{~m}^{3} / \mathrm{s}$ & 3.306 & 3.429 & 3.130 & 2.408 & 0.871 \\
& 3.184 & 3.524 & 3.266 & 2.449 & 0.857 \\
\hline & 3.674 & 4.477 & 4.490 & 3.266 & 1.320 \\
$0,0078 \mathrm{~m}^{3} / \mathrm{s}$ & 3.796 & 4.477 & 3.878 & 3.306 & 1.333 \\
& 3.674 & 4.572 & 3.810 & 3.266 & 1.320 \\
\hline
\end{tabular}

Pada penelitian ini diberikan tiga variasi debit aliran yaitu $0,0056 \mathrm{~m}^{3} / \mathrm{s}, 0,0067 \mathrm{~m}^{3} / \mathrm{s}$ dan $0,0078 \mathrm{~m}^{3} / \mathrm{s}$ dan juga lima variasi putaran yaitu
$90 \mathrm{rpm}, 70 \mathrm{rpm}, 50 \mathrm{rpm}, 30 \mathrm{rpm}$ dan $10 \mathrm{rpm}$. Hubungan antara daya dan debit air pada variasi putaran seperti ditunjukkan Gambar 5.

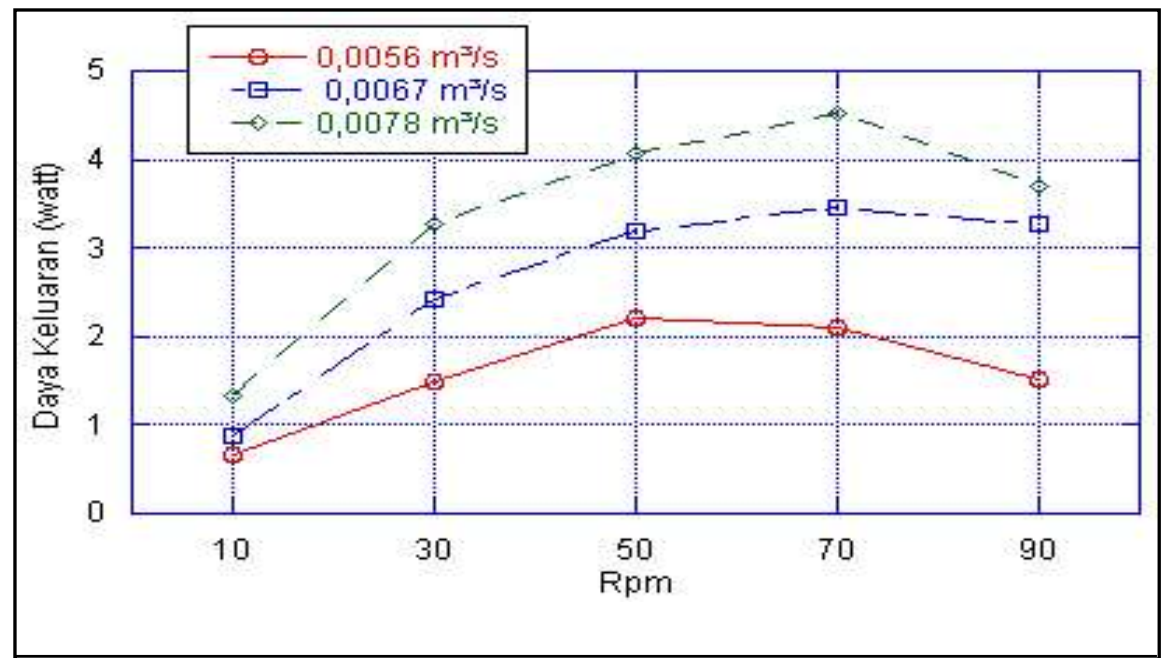

Gambar 5. Perubahan daya keluaran terhadap kecepatan runner

Dari variasi puratan runner yang menunjukan perubahan daya maksimum terjadi pada putaran $50 \mathrm{rpm}, 70 \mathrm{rpm}$ dan $90 \mathrm{rpm}$. Daya maksimum diperoleh pada kecepatan runner 70 rpm dengan debit aliran $0,0078 \mathrm{~m}^{3} / \mathrm{s}$ sebesar 4.572 watt. Jika kecepatan debit diperbesar maka besar daya keluaran akan besar pula tetapi berbantung pada besar putaran runner. Daya minumum dihasilkan pada debit $0,0078 \mathrm{~m}^{3} / \mathrm{s}$ terjadi pada kecepatan runner $90 \mathrm{rpm}$ sebesar 3,674 watt. Daya turbin sangat tergantung pada besarnya torsi dan kecepatan anguler. Sedangkan kecepatan anguler dipengaruhi oleh putaran turbin dan putaran turbin sangat 
tergantung dari massa aliran yang menumbuk sudu turbin.

Debit air dipengaruhi oleh kecepatan air dan berpengaruh terhadap massa aliran, putaran turbin, torsi turbin, dan daya turbin. Semakin besar debit air maka daya turbin kinetik semakin meningkat dikarenakan adanya penambahan kecepatan aliran dan massa aliran yang menumbuk sudu turbin sehingga gaya tangensial yang dihasilkan meningkat dan gaya tangensial tersebut mempengaruhi torsi turbin, dan daya turbin kinetik. Hasil perhitungan efisiensi ditunjukan pada Tabel 3.

Tabel 3. Data efisiensi tiap putaran runner turbin terhadap debit air.

\begin{tabular}{cccccc}
\hline \multirow{2}{*}{ Debit, Q m³/s } & \multicolumn{5}{c}{ Efisiensi $\eta(\%)$} \\
\cline { 2 - 6 } & $90 \mathrm{rpm}$ & $70 \mathrm{rpm}$ & $50 \mathrm{rpm}$ & $30 \mathrm{rpm}$ & $10 \mathrm{rpm}$ \\
\hline $0,0056 \mathrm{~m}^{3} / \mathrm{s}$ & 3.241 & 4.266 & 4.571 & 3.075 & 1.357 \\
& 2.992 & 4.266 & 4.433 & 3.075 & 1.357 \\
& 2.992 & 4.266 & 4.433 & 2.992 & 1.357 \\
\hline $0,0067 \mathrm{~m}^{3} / \mathrm{s}$ & 14.312 & 14.842 & 13.840 & 10.424 & 3.769 \\
& 14.312 & 14.842 & 13.546 & 10.424 & 3.769 \\
& 13.781 & 15.254 & 14.135 & 10.601 & 3.710 \\
\hline $0,0078 \mathrm{~m}^{3} / \mathrm{s}$ & 23.189 & 28.256 & 28.342 & 20.612 & 8.331 \\
& 23.962 & 28.256 & 24.477 & 20.870 & 8.417 \\
& 23.189 & 28.857 & 24.048 & 20.612 & 8.331 \\
\hline
\end{tabular}

Pada penelitian ini diberikan tiga variasi debit aliran yaitu $0,0056 \mathrm{~m}^{3} / \mathrm{s}, 0,0067 \mathrm{~m}^{3} / \mathrm{s}$ dan $0,0078 \mathrm{~m}^{3} / \mathrm{s}$ dan juga lima variasi putaran yaitu $90 \mathrm{rpm}, 70 \mathrm{rpm}, 50 \mathrm{rpm}, 30 \mathrm{rpm}$ dan $10 \mathrm{rpm}$.
Hubungan antara efisiensi dan debit air pada variasi putaran seperti ditunjukkan Gambar 6.

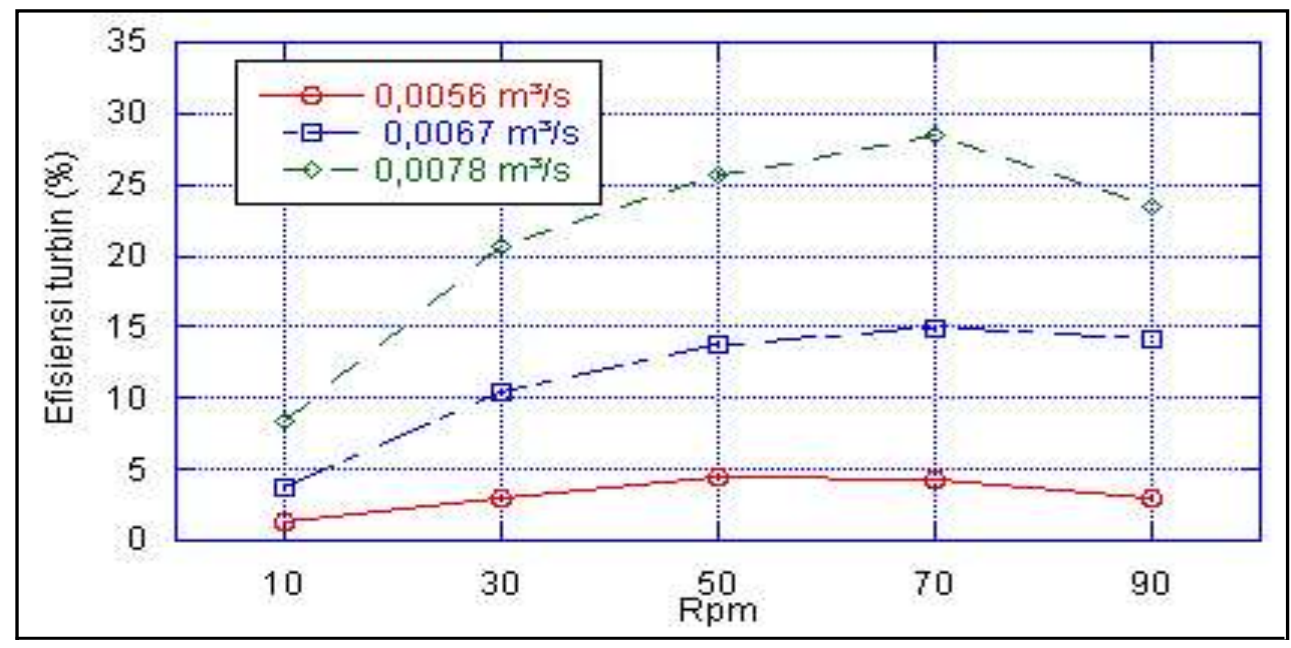

Gambar 6. Perubahan efisiensi keluaran terhadap kecepatan runner 
Berdasarkan gambar 6 efisiensi turbin maksimum terjadi pada debit aliran $0,0078 \mathrm{~m}^{3} / \mathrm{s}$ dan $70 \mathrm{rpm}$ dengan nilai sebesar $28.342 \%$, kemudian menurun pada putaran $50 \mathrm{rpm}$ sebesar $24.477 \%$ dan yang terendah pada putaran $90 \mathrm{rpm}$ sebesar $23.189 \%$. Dari hasil perhitungan efisiensi diperoleh nilai efisiensi maksimum diperoleh dengan kecepatan runner $70 \mathrm{rpm}$ dengan aliran debit $0,0078 \mathrm{~m}^{3} / \mathrm{s}$. Efisiensi turbin sangat tergantung pada besarnya daya turbin dan daya turbin sangat tergantung pada besarnya torsi dan kecepatan anguler. Sedangkan kecepatan anguler dipengaruhi oleh putaran turbin dan putaran turbin sangat tergantung dari massa aliran yang menumbuk sudu turbin.

\section{KESIMPULAN}

1. Daya turbin sangat tergantung pada besarnya torsi dan kecepatan anguler. Sedangkan kecepatan anguler dipengaruhi oleh putaran turbin dan putaran turbin sangat tergantung dari massa aliran yang menumbuk sudu turbin.

2. Efisiensi turbin sangat tergantung pada besarnya daya turbin dan daya turbin sangat tergantung pada besarnya torsi dan kecepatan anguler.

3. Semakin besar debit air maka efisiensi turbin kinetik semakin meningkat dikarenakan adanya penambahan kecepatan aliran dan massa aliran yang menumbuk sudu turbin sehingga gaya tangensial yang dihasilkan meningkat dan gaya tangensial tersebut mempengaruhi torsi turbin, daya turbin dan efisiensi turbin kinetik.

\section{DAFTAR KEPUSTAKAAN}

Arismunandar W. 2004. Penggerak mula turbin, edisi ketiga. Bandung: ITB.

Arismunandar W. 1982. Penggerak Mula Turbin. Bandung: ITB.

Bono dan Indarto. 2008. Karakterisasi daya turbin Pelton mikro dengan variasi bentuk sudu. Seminar Nasional Aplikasi Sains dan Teknologi 2008 - IST AKPRIND Yogyakarta.

Haimerl LA. 1960. The crossflow turbine. Jerman Barat. Hal 3.

Luknanto D. 2008. Diktat Kuliah Bangunan Tenaga Air. Surabaya: ITS.

Triono M. 2012. Pemodelan Turbin Cross-Flow Untuk Diaplikasikan Pada Sumber Air Dengan Tinggi Jatuh dan Debit Kecil. Jurnal Nutrino, Vol. 4 No. 2. Malang: Fakultas Saintek, UIN Maliki.

Raharjo T. 2008. Pengaruh variasi profil sudu pada runner terhadap efisiensi yang dihasilkan oleh turbin air pelton. Seminar Nasional Aplikasi Sains dan Teknologi 2008-Semarang.

Soenoko R. 2012. Dual Kinetic Turbine Optimization as A Rural Electricity Power Generation. Prosiding Seminar Nasional Science, Engineering and Technology. Brawijaya Malang.

Zahri KM dan Bambang. 2010. Pengaruh tinggi sudu kincir air terhadap daya dan efisiensi yang dihasilkan. Seminar Nasional Tahunan Teknik Mesin (SNTTM) ke-9 Palembang. 13-15. 